\title{
Correction of TRMM 3B42V7 Based on Linear Regression Models over China
}

\author{
Shaohua Liu, Denghua Yan, Tianling Qin, Baisha Weng, and Meng Li \\ China Institute of Water Resources and Hydropower Research (IWHR), State Key Laboratory of Simulation and \\ Regulation of Water Cycle in River Basin, Beijing 100038, China
}

Correspondence should be addressed to Denghua Yan; yandh@iwhr.com

Received 4 August 2016; Revised 7 October 2016; Accepted 7 November 2016

Academic Editor: Pedro Jiménez-Guerrero

Copyright (C) 2016 Shaohua Liu et al. This is an open access article distributed under the Creative Commons Attribution License, which permits unrestricted use, distribution, and reproduction in any medium, provided the original work is properly cited.

High temporal-spatial precipitation is necessary for hydrological simulation and water resource management, and remotely sensed precipitation products (RSPPs) play a key role in supporting high temporal-spatial precipitation, especially in sparse gauge regions. TRMM 3B42V7 data (TRMM precipitation) is an essential RSPP outperforming other RSPPs. Yet the utilization of TRMM precipitation is still limited by the inaccuracy and low spatial resolution at regional scale. In this paper, linear regression models (LRMs) have been constructed to correct and downscale the TRMM precipitation based on the gauge precipitation at 2257 stations over China from 1998 to 2013. Then, the corrected TRMM precipitation was validated by gauge precipitation at 839 out of 2257 stations in 2014 at station and grid scales. The results show that both monthly and annual LRMs have obviously improved the accuracy of corrected TRMM precipitation with acceptable error, and monthly LRM performs slightly better than annual LRM in Mideastern China. Although the performance of corrected TRMM precipitation from the LRMs has been increased in Northwest China and Tibetan plateau, the error of corrected TRMM precipitation is still significant due to the large deviation between TRMM precipitation and low-density gauge precipitation.

\section{Introduction}

Precipitation plays a vital role in global energy and water cycle exchanges, connecting the hydrosphere, atmosphere, lithosphere, and biosphere [1]. The reliable spatial-temporal measurement of regional and global precipitation is critical for the hydrological modelling (particularly in distributed hydrological model), water resource management, and the prevention of natural disasters $[2,3]$. However, the reliable and accurate estimation of precipitation remains a challenge due to the high spatial-temporal variability of climate and underlying heterogeneity $[3,4]$.

Despite the insufficient spatial resolution of conventional precipitation gauges, gauge precipitation is still the most accurate source of direct precipitation measurement and continues to be the critical role in documenting the precipitation characteristics over regional and global land attributed to the long-term recording period [5-7]. Several datasets of precipitation products have been constructed over regional and global domains based on the gauge precipitation: CRU TS3.1 monthly grid precipitation dataset during 1901-2009 covers all land areas of earth with spatial resolution $0.5^{\circ}$ [8]; Global Precipitation Climatology Center (GPCC) datasets with spatial resolution of $0.5^{\circ}$ use the station database (SYNOP, CLIMAT) available via the Global Telecommunication System (GTS) of the World Meteorological Organization (WMO) from 1901 to 2010 [9]; CPC unified gaugebased analysis of global daily precipitation has been constructed on a $0.125^{\circ}$ resolution over the entire global land and is released at $0.5^{\circ}$ resolution over the global domain from 1979 to the present (https://climatedataguide.ucar.edu/ climate-data/cpc-unified-gauge-based-analysis-global-dailyprecipitation); and other regional gauge based precipitation datasets [10-13]. Accordingly, the gauge based precipitation datasets were widely applied into the climate diagnostics and hydrological researches [2,13-17]. Nevertheless, the utilization of gauge precipitation products is limited in the area with nongauge/sparse gauge networks such as ocean, 
desert, and mountainous area, especially in developing countries $[3,4,7]$, due to the low spatial resolution and inaccuracy.

In order to better understand the spatial distribution of precipitation, some high resolution precipitation products based on the remote sensing data (infrared, passive microwave radiometers, and precipitation radar) and gauge precipitation have been produced in recent years: Global Precipitation Climatology Project (GPCP) product provides monthly precipitation products on $2.5^{\circ}$ grid from 1979 to the present [18] and daily precipitation estimation on $1^{\circ}$ grid over the entire globe from October 1996 to the present [19]; Precipitation Estimation from Remotely Sensed Information using Artificial Neural Networks (PERSIANN) is a satellitebased precipitation retrieval algorithm that provides near real-time precipitation information, and the precipitation dataset covers $50^{\circ} \mathrm{S}$ to $50^{\circ} \mathrm{N}$ globally at a $0.25^{\circ}$ resolution and is available from March 2000 to the present [20, 21]; CMORPH (CPC Morphing technique) produces global precipitation analyses covering $50^{\circ} \mathrm{S}$ to $50^{\circ} \mathrm{N}$ globally at a very high spatial $\left(0.07277^{\circ}\right)$ and temporal (30 minute) resolution from 2002 to the present; TRMM Multisatellite Precipitation Analysis generates a series of the most widely used precipitation products with a near-global coverage and adequate spatialtemporal resolution from 1997 to the present $[22,23]$.

Accordingly, the aforementioned precipitation products were employed in a wide range of applications consisting of hydrological researches [24, 25], flood and drought monitors $[26,27]$, and climatic diagnosis [28] and compared globally $[29,30]$ and in different countries including US [31, 32], China [2, 33], Italy [34], Iran [7, 35-37], Peru [38], Greece [4, 39], and Saudi Arabia [40]. Most results indicated that the TRMM product (especially the TRMM version 7) outperforms the other remote sensing precipitation products (RSPPs). TRMM version 7 (TRMM V7) released in May 2012 contains two kinds: the real-time gridded precipitation product (3B42RTV7) with a near-global $\left(60^{\circ} \mathrm{N}-60^{\circ} \mathrm{S}\right)$ coverage and a gauge-adjusted, post-real-time research product (3B42V7) with coverage from $50^{\circ} \mathrm{N}-50^{\circ} \mathrm{S}$. Both 3B42RTV7 and 3B $42 \mathrm{~V} 7$ have a high spatial $\left(0.25^{\circ}\right)$ and temporal (3 hour) resolution. Numerous researches have pointed out that the TRMM V7 improves upon TRMM V6 in different countries including continental United States and China, notably the research product 3B42V7 [2, 32].

Although TRMM 3B42V7 (TRMM precipitation) has been verified more realistically than other RSPPs, the utilization of TRMM precipitation is still limited by its regional inaccuracy and low resolution. Moreover, the real-time and high-density gauge precipitation is not available, and the open access gauge precipitation is always limited with lowdensity, particularly in developing countries such as China. As a result, high resolution precipitation remains a challenge to the scientific community and public in China [2, 41, 42]. Nevertheless, several researches have shown that there is a good relation between TRMM precipitation and gauge precipitation [2, 25, 43], yet rare effort has been focused on the quantitative relation between TRMM precipitation and gauge precipitation. Therefore, the objective of this paper is to construct linear regression models (LRMs) in order to correct and downscale TRMM precipitation based on the historical long-term and high-density gauge precipitation, and then the real-time and high resolution precipitation can be obtained from the timely TRMM precipitation through LRMs with the parameters estimated by the historical precipitation. To this regard, the suitable temporal scale was identified to correct the TRMM precipitation based on the relation between TRMM precipitation and gauge precipitation; then the TRMM precipitation was corrected and validated by the LRMs at different time scales. The paper is organized as follows: Section 2 describes the study area and data preparation. Section 3 provides a brief introduction of statistical indices and LRMs. Section 4 presents the results and discussions, and the conclusions are given in Section 5.

\section{Study Area and Data}

2.1. Study Area. China is located in East Asia along the Pacific Ocean, and the spatial-temporal distribution of precipitation in China is mainly affected by the East Asian monsoon. Besides, the terrain is complex and altitude is increasing from negative (eastern plains) to higher than $8000 \mathrm{~m}$ (Tibetan plateau) (Figures 1(a) and 1(c)). Consequently, precipitation gradually decreases from southwest to the northwest, except in the Tibetan plateau with complex terrain which is affected by the southwest monsoon [2]. With the seasonal movement of East Asia monsoon over China domain, annual precipitation is unevenly distributed at temporal scale (Figure 1(b)) and varied in different regions. Thus, the China mainland is divided into three regions, that is, Mideastern China, Northwest China, and Tibetan plateau (Figure 1(a)).

2.2. Data Preparation. Daily gauge precipitation at 2257 stations over China (under the TRMM data coverage, Figure 1(a)) from 1998 to 2013 is the most complete meteorological precipitation provided by National Meteorological Information Center (not available to the public) and considered as the basic reference precipitation to correct and downscale TRMM precipitation via LRMs. Moreover, daily gauge precipitation at 839 out of 2257 stations in 2014 is an open access dataset provided by the China Meteorological Data Sharing Service System (http://cdc.nmic.cn/home.do) and is used to validate the corrected TRMM precipitation from LRMs.

TRMM 3B42 version 7 product from 1998 to 2013, 3hourly temporal and $0.25^{\circ} \times 0.25^{\circ}$ spatial scales, was originated from the National Aeronautics and Space Administration (NASA) and the Japan Aerospace Exploratory Agency (JAXA) and had been accumulated into daily/monthly/ annual scales over China. It is necessary to note that there are about 500 out of 2257 stations used into GPCC datasets, which were utilized to validate the TRMM dataset. Thus, the TRMM dataset is not independent of gauge precipitation data $[2,32]$.

To compare the TRMM precipitation and gauge precipitation at station and grid scales, the daily TRMM precipitation at 2257 stations was obtained from grids covering the corresponding stations and was accumulated into monthly and annual TRMM precipitation. Then TRMM precipitation 


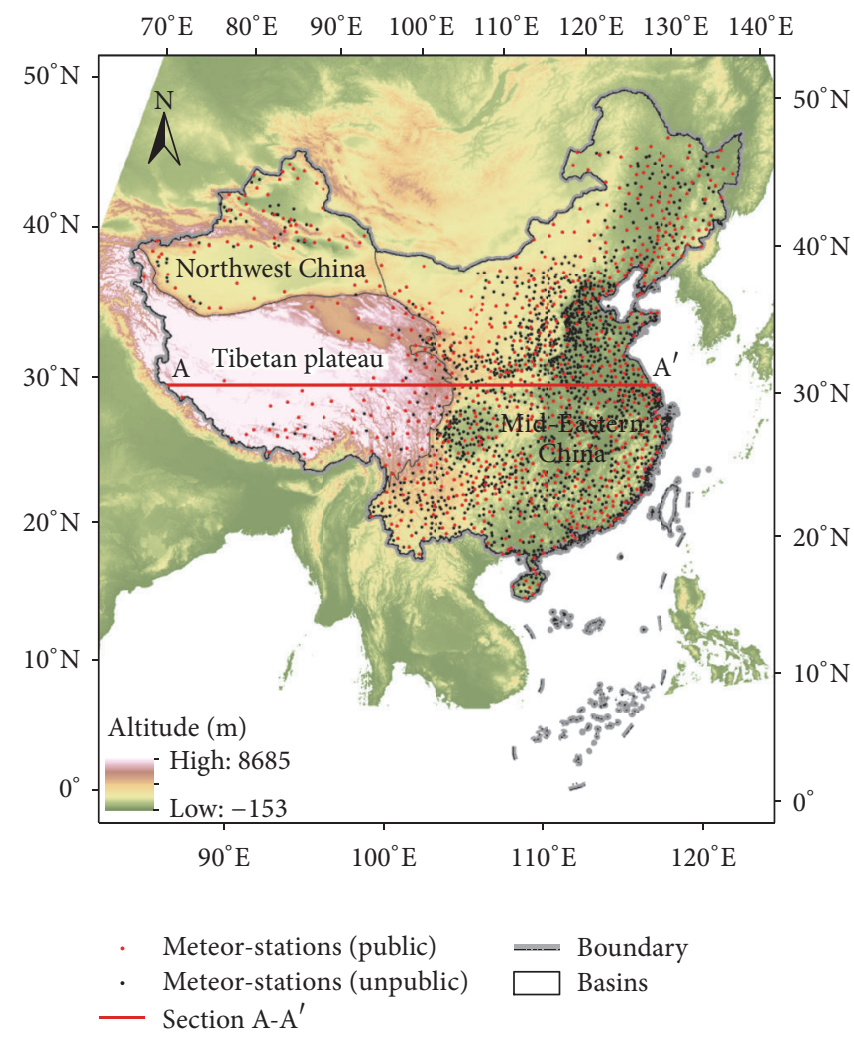

(a)

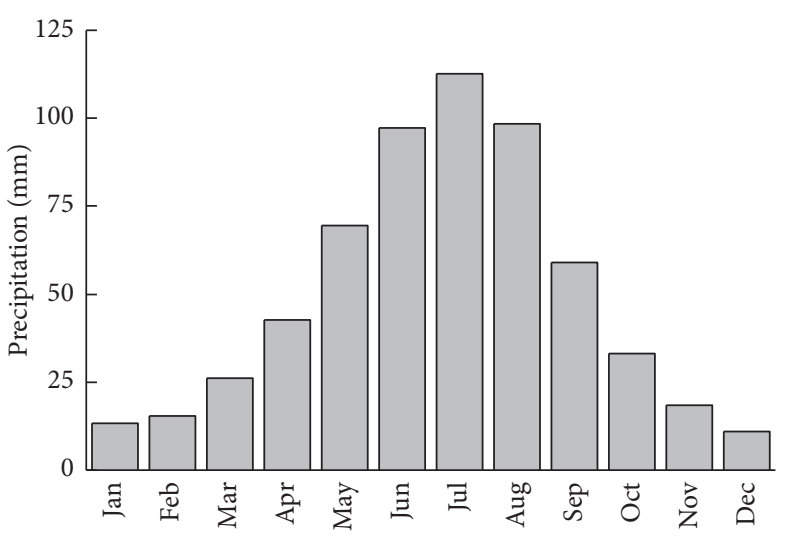

(b)

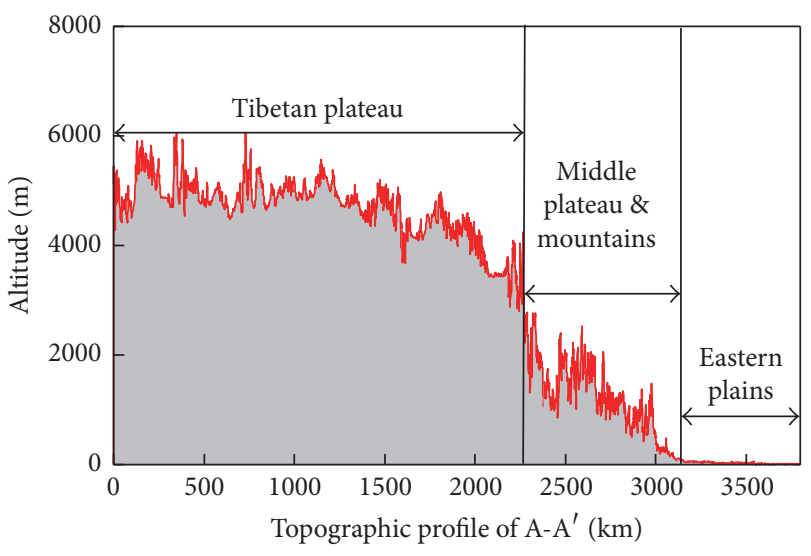

(c)

FIGURE 1: Topographical map of China and geographic distribution of the precipitation gauges (a), distribution of average monthly precipitation (b), and a typical topographic profile across China (c).

at 2257 stations was evaluated based on the gauge precipitation at station scale. Moreover, in order to evaluate the detailed spatial distribution of TRMM precipitation over China domain at grid scale, the TRMM precipitation was resampled into grids at $1 \mathrm{~km}$ resolution, which is the most common resolution for TRMM precipitation downscaling [44-46]. Correspondingly, the monthly gauge precipitation was interpolated into grids with $1 \mathrm{~km}$ resolution as the reference precipitation by the Inverse Distance Weighting (IDW) with a variable search radius of 8 nearest gauge stations. The IDW is a certain interpolation method and has been confirmed to be a suitable interpolation for precipitation in China, especially with the a dense gauge network $[47,48]$.

\section{Methods}

3.1. Statistical Indices. In order to identify the suitable time scale to construct the LRM between TRMM precipitation and gauge precipitation, the Pearson Correlation Coefficient (PCC) was employed to analyse the relation between gauge precipitation and TRMM precipitation at different time scales. Furthermore, Root Mean Square Error (RMSE) 
and Bias were applied to validate the TRMM precipitation, expressed as follows:

$$
\begin{aligned}
\text { PCC } & =\frac{\operatorname{Cov}\left(P^{\text {TRMM }}, P^{\text {Gauge }}\right)}{\sqrt{\operatorname{Var}\left(P^{\text {TRMM }}\right)} \sqrt{\operatorname{Var}\left(P^{\text {Gauge }}\right)}} \\
\text { RMSE } & =\sqrt{\frac{\sum_{i=1}^{n}\left(P_{i}^{\text {TRMM }}-P_{i}^{\text {Gauge }}\right)^{2}}{n}} \\
\text { Bias } & =\frac{\overline{P^{\text {TRMM }}}-\overline{P^{\text {Gauge }}}}{\overline{P^{\text {Gauge }}}},
\end{aligned}
$$

where $P^{\text {TRMM }}$ and $P^{\text {Gauge }}$ are annual or monthly TRMM precipitation and gauge precipitation and $\overline{P^{\text {TRMM }}}$ and $\overline{P^{\text {Gauge }}}$ are the average values of $P^{\mathrm{TRMM}}$ and $P^{\mathrm{Gauge}}$, respectively.

3.2. Linear Regression Model. The LRM was applied to quantify the statistic relation between TRMM precipitation and gauge precipitation at grid and regional scales. The offset parameter $a$ and scale parameter $b$ can be estimated by the ordinary least squares methods (OLS) as (3) and (4), and $R^{2}$ and $F$ test statistic are used to identify whether the LRM fits into the relation between TRMM precipitation and gauge precipitation and formulated as (5) and (6).

$$
\begin{aligned}
P^{\text {Gauge }} & =a+b P^{\mathrm{TRMM}}+\varepsilon \\
\widehat{b} & =\frac{\sum_{i=1}^{n}\left(P_{i}^{\mathrm{Gauge}}-\overline{P^{\mathrm{Gauge}}}\right)\left(P_{i}^{\mathrm{TRMM}}-\overline{P^{\mathrm{TRMM}}}\right)}{\sum_{i=1}^{n}\left(P_{i}^{\mathrm{TRMM}}-\overline{P^{\mathrm{TRMM}}}\right)^{2}} \\
\widehat{a} & =\overline{P^{\text {Gauge }}}-\widehat{b} \overline{P^{\mathrm{TRMM}}} \\
R^{2} & =\frac{\sum_{i=1}^{n}\left(\overline{P_{i}^{\text {Gauge }}}-\overline{P^{\mathrm{TRMM}}}\right)^{2}}{\sum_{i=1}^{n}\left(P_{i}^{\text {Gauge }}-\overline{P^{\mathrm{TRMM}}}\right)^{2}} \\
F & =\frac{\sum_{i=1}^{n}\left(\left(\overline{P_{i}^{\text {Gauge }}}-\overline{P^{\mathrm{TRMM}}}\right)^{2} / k\right)}{\sum_{i=1}^{n}\left(\left(P_{i}^{\text {Gauge }}-\overline{P_{i}^{\text {Gauge }}}\right)^{2} /(n-k-1)\right)} \\
& \sim F(k, n-k-1) \\
\widehat{P_{i}^{\text {Gauge }}} & =\widehat{a}+\widehat{b} P_{i}^{\mathrm{TRMM}},
\end{aligned}
$$

where $P_{i}^{\mathrm{TRMM}}$ and $P_{i}^{\text {Gauge }}$ are TRMM precipitation and gauge precipitation in month/year $i$, respectively, $\overline{P_{i}^{\mathrm{TRMM}}}$ and $\overline{P^{\mathrm{TRMM}}}$ are average monthly/annual precipitation from January 1998 to December 2013, $\widehat{a}, \hat{b}$ are the estimation of offset and scale parameter, separately, $\varepsilon$ is the random error, and $n$ is the length of series ( $n=192$ at monthly scale; $n=16$ at annual scale).

According to the previous researches, there is a good relation between gauge precipitation and TRMM precipitation at monthly and annual scales $[2,25,49]$. Consequently,

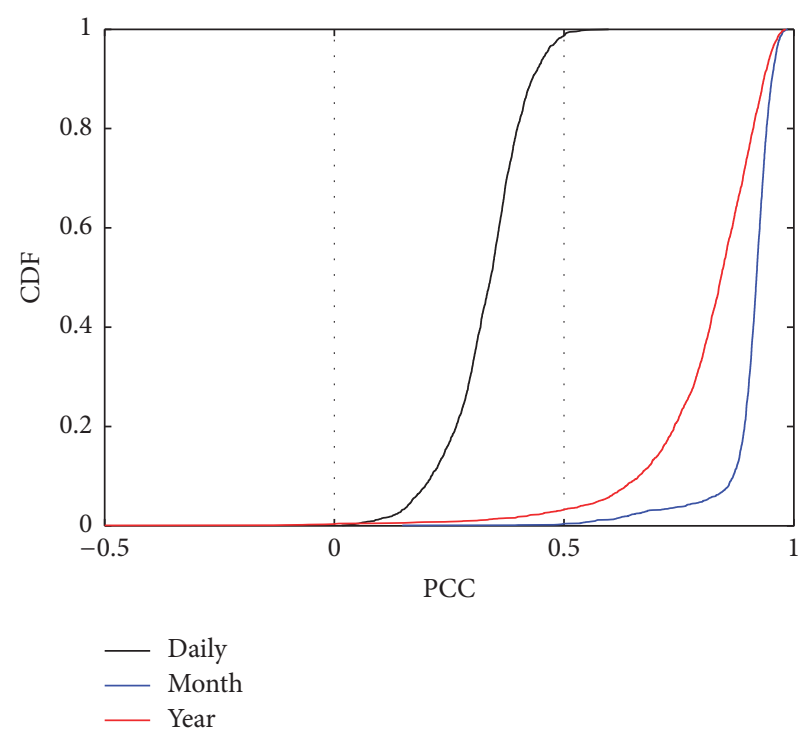

FIGURE 2: PCCs between gauge precipitation and TRMM precipitation in 2257 stations.

the LRMs were constructed based on monthly and annual relation between gauge precipitation and TRMM precipitation, separately. For the monthly LRM, monthly corrected TRMM precipitation can be calculated from monthly gauge precipitation based on the monthly LRM, and annual corrected TRMM precipitation was accumulated by the monthly corrected TRMM precipitation. For the annual LRM, annual corrected TRMM precipitation was obtained from annual gauge precipitation based on annual LRM, and monthly corrected TRMM precipitation was computed by the following:

$$
\widehat{P_{i, j}^{\text {Gauge }}}=\frac{P_{i, j}^{\text {TRMM }}}{P_{i}^{\text {TRMM }}} \overline{P_{i}^{\text {Gauge }}},
$$

where $\widehat{P_{i, j}^{\text {Gauge }}}$ and $\widehat{P_{i}^{\text {Gauge }}}$ are the monthly and annual corrected TRMM precipitation of $j$ th month $(j=1,2, \ldots, 12)$ and $i$ th year $(i=1998,1999, \ldots, 2013)$ from annual LRM and $P_{i, j}^{\mathrm{TRMM}}$ and $P_{i}^{\mathrm{TRMM}}$ are the corresponding original TRMM precipitation.

\section{Results and Discussions}

4.1. Correlations between Gauge Precipitation and TRMM Precipitation. Relation between gauge precipitation and TRMM precipitation is complicated not only in spatial distribution but also in temporal scales. Hence, a suitable time scale is important for the correction of TRMM precipitation. The cumulative distribution function (CDF) of PCCs between gauge precipitation and TRMM precipitation at 2257 stations at different time scales during 1998-2013 is shown in Figure 2. It can be seen that the PCCs at monthly and annual scales are significantly larger than the PCC at daily scale. It implies that TRMM precipitation at monthly and annual scales, especially at monthly scale, is in good agreement with gauge precipitation, which agrees with the previous researches [7, 38]. Furthermore, the monthly and annual PCCs between 


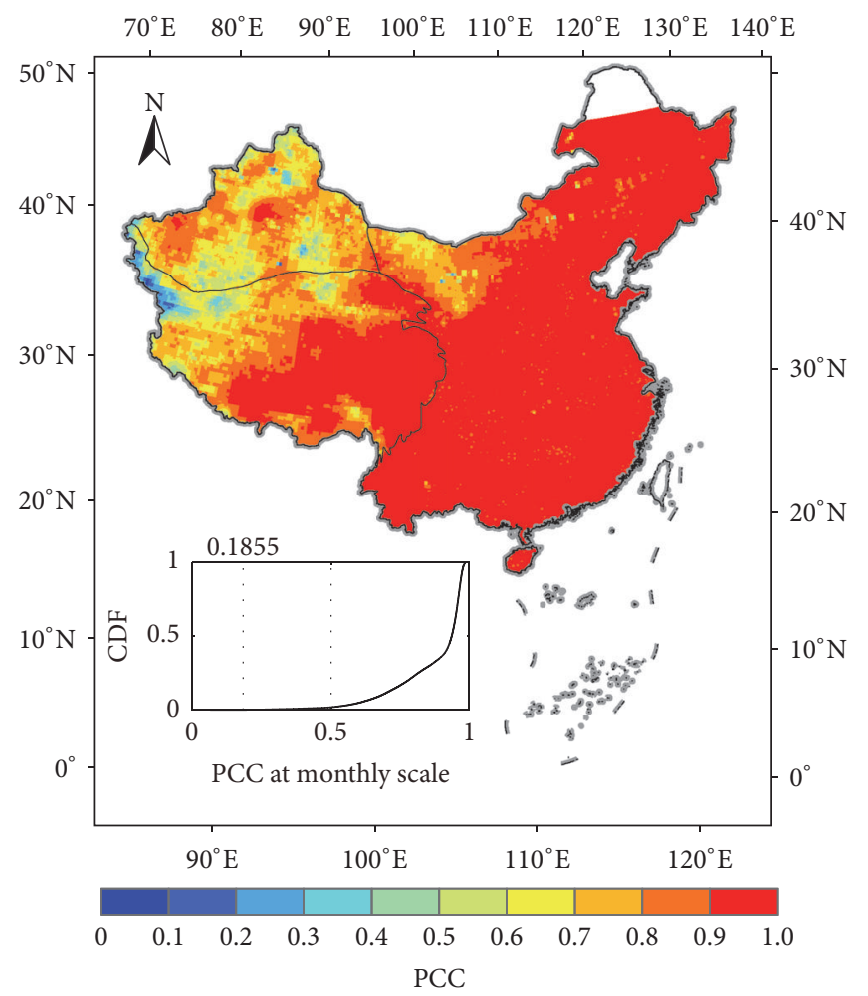

(a)

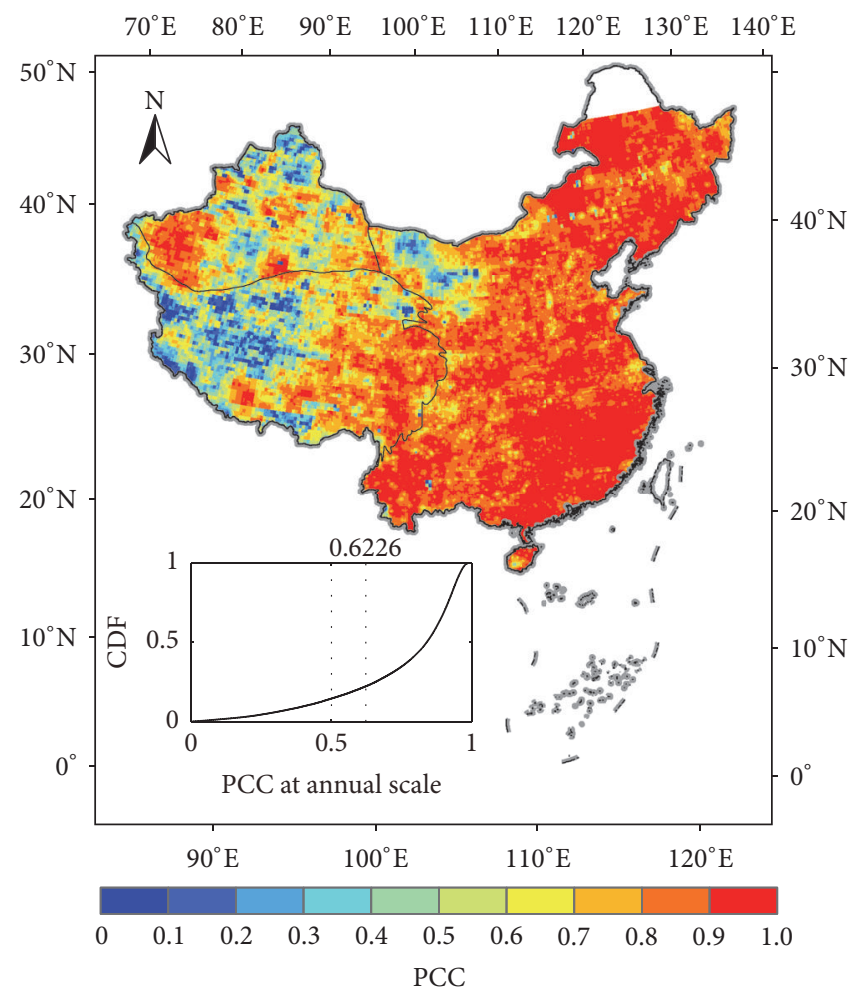

(b)

FIGURE 3: Distribution of PCCs between grid gauge precipitation and TRMM precipitation at monthly and annual scales over China.

grid gauge precipitation and TRMM precipitation at $1 \mathrm{~km}$ resolution are figured out in Figure 3. It can be seen that there are more than $99.9 \%$ of total grids with significant PCC at the level of $\alpha=0.01\left(\mathrm{PCC}_{\alpha=0.01, n=192}=0.1855\right)$ at monthly scale and only about three quarters of total grids with significant PCC at the level of $\alpha=0.01\left(\mathrm{PCC}_{\alpha=0.01, n=16}=0.6226\right)$ at annual scale. Additionally, the grids with low PCCs value are mostly located in Northwest China and Tibetan plateau with sparse gauge networks.

4.2. Linear Regression Model Results. The LRMs are constructed to correct and downscale the original TRMM precipitation at monthly and annual scales, separately. Figure 4 shows the results of monthly LRM; the offset parameter $a$ ranging from -45 to 55 over China mostly concentrates in the range between -10 and 10 (Figure 4(a)). Meanwhile, the scale parameter $b$ is ranging from 0.7 to 1.2 in Eastern China and is unevenly distributed in Northwest China and Tibetan plateau (Figure 4(b)). Figure 4(c) sheds light on $R^{2}$ of the LRM, and it illustrates that $R^{2}$ is significantly larger than 0.6 over China, except for Northwest China and Tibetan plateau. The $F$ statistic of the LRM is distributed in Figure 4(d); it can be seen that there was about $1.0 \times 10^{5} \mathrm{~km}^{2}$ accounting for $0.1 \%$ of China mainland with $F$ statistic under 6.77 (the threshold at the 0.01 significant level when $n=192$ ), which indicates that monthly LRM is suitable for the correction of TRMM precipitation over China.

The results of annual LRM are displayed in Figure 5. It illustrates that the range of offset parameter $a$ is obviously larger and more unevenly distributed than that in monthly LRM over China (Figure 5(a)). The distribution of scale parameter $b, R^{2}, F$ test value are consistent with that in monthly LRM (Figures 5(b)-5(d)), yet the value of $R^{2}$ and $F$ statistic exhibit an apparent decrease. The reason is that the length of input series in annual model $(n=16)$ is obviously less that in monthly LRM $(n=192)$, which has a profound influence on the parameter estimation and model test from a statistical standpoint. As a result, parameters $a$ and $b$ are more uncertain and unevenly distributed, and the value of $R^{2}$ and $F$ statistic are significantly decreased. Based on the significance test result (Figure 5(d)), there is about $2.06 \times$ $10^{6} \mathrm{~km}^{2}$, accounting for about $21 \%$ of China mainland, with the $F$ statistic under 8.86 (the threshold at 0.01 significant level when $n=16$ ) mainly located in Northwest China and Tibetan plateau. Compared with $F$ statistic result in monthly LRM, it can be inferred that monthly LRM is more suitable for the correction of TRMM precipitation over China from a statistical standpoint.

\subsection{Validation of Linear Regression Models}

4.3.1. Validation at Station Scale. The gauge precipitation at 839 stations in 2014 was used to validate original TRMM precipitation (TRMM prec0), TRMM precipitation corrected by monthly LRM (TRMM prec1), and TRMM precipitation corrected by annual LRM (TRMM prec2). The scatterplots of annual gauge precipitation versus original/corrected TRMM precipitation in the three regions at station scale are shown 


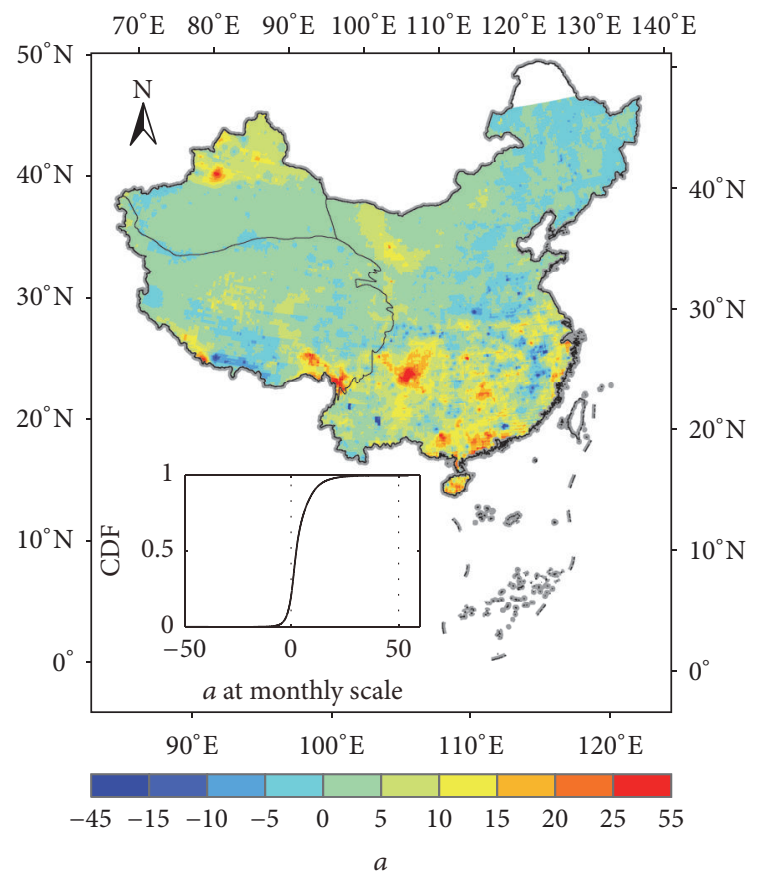

(a)

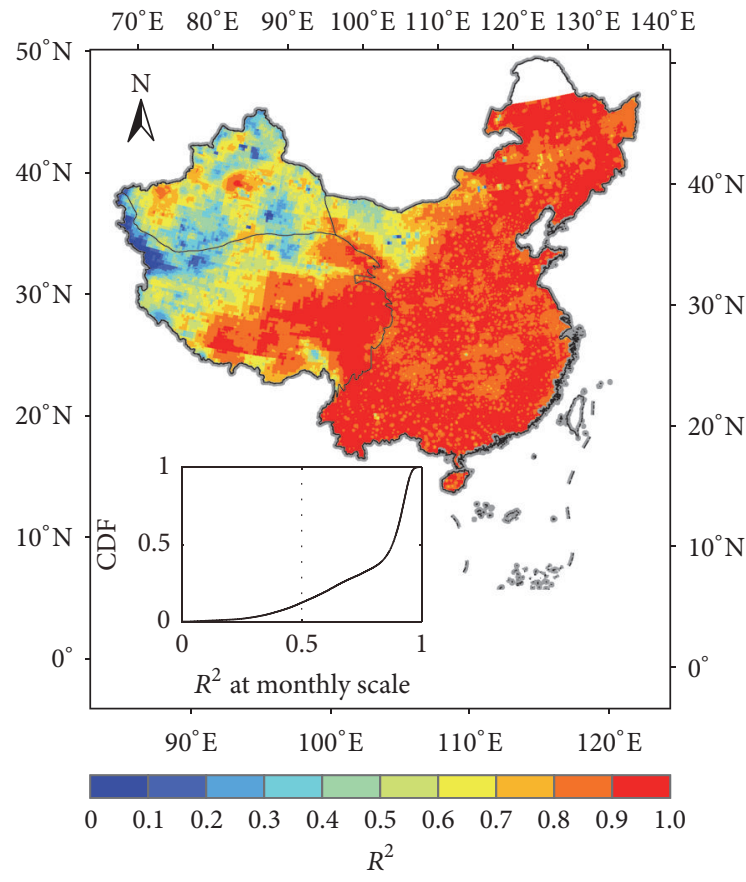

(c)

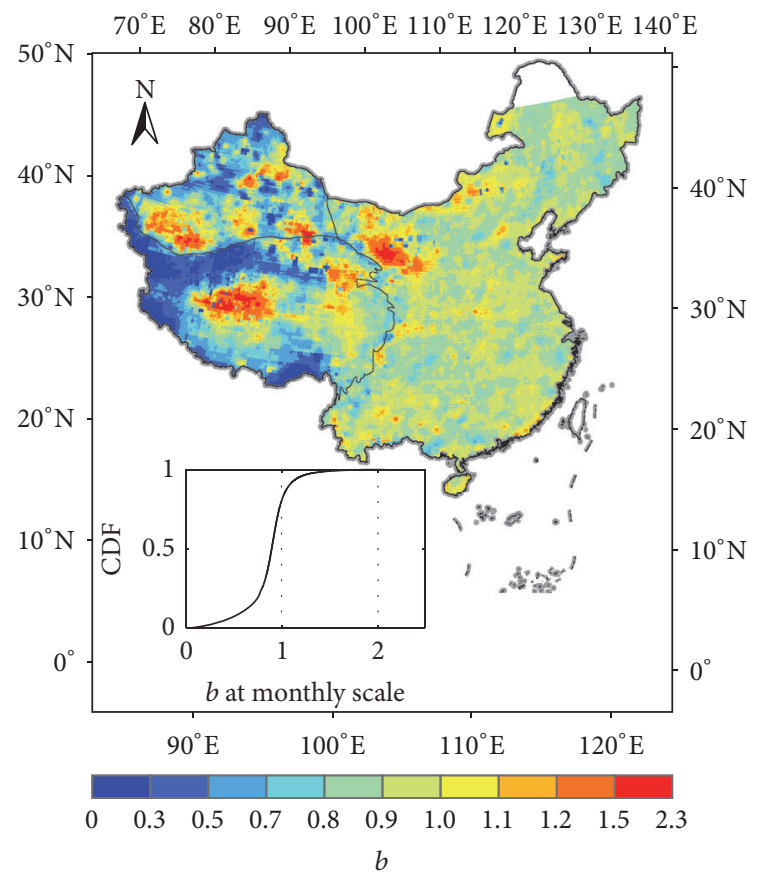

(b)

$70^{\circ} \mathrm{E} \quad 80^{\circ} \mathrm{E} \quad 90^{\circ} \mathrm{E} \quad 100^{\circ} \mathrm{E} 110^{\circ} \mathrm{E} 120^{\circ} \mathrm{E} 130^{\circ} \mathrm{E} 140^{\circ} \mathrm{E}$

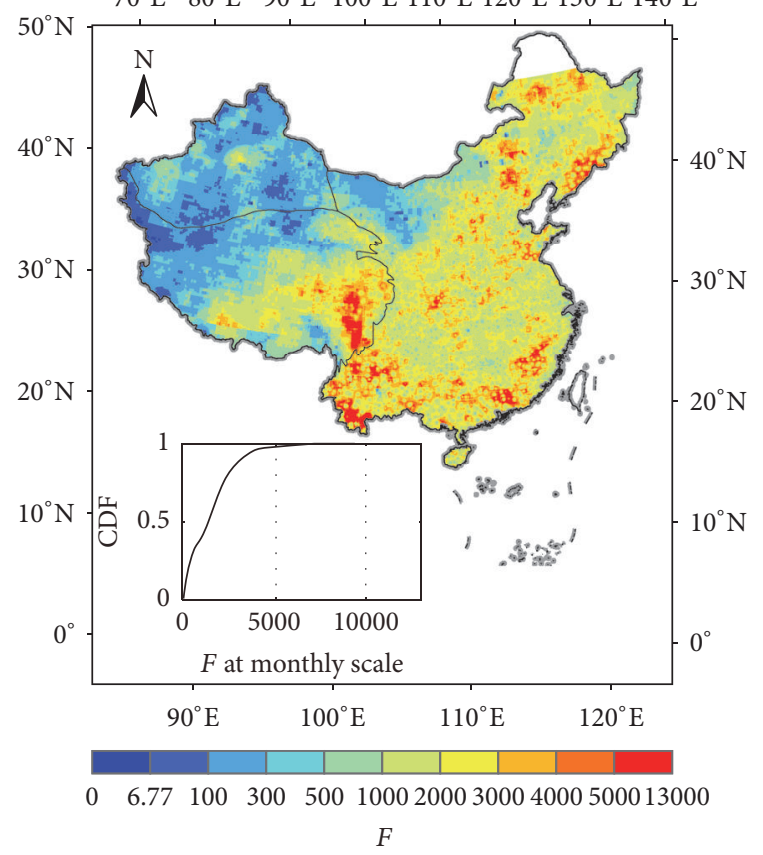

(d)

FIgURe 4: Monthly linear regression model result over China: (a) offset parameter $a$, (b) scale parameter $b$, (c) $R^{2}$, and (d) $F$ statistic.

in Figure 6. It can be seen that two LRMs have obviously improved the precipitation accuracy compared to the original TRMM precipitation with increased $R^{2}$ and decreased RMSE and Bias, and monthly LRM performs slightly better than annual LRM with smaller RMSE in Mideastern China. Figure 7 displays the scatterplots of monthly gauge precipitation versus original/corrected TRMM precipitation in the three regions at station scale. In comparison of the relations between gauge precipitation and original TRMM precipitation in the three regions, the original TRMM precipitation in Northwest China deviates more from the gauge precipitation at station scale than that in Mideastern China and Tibetan plateau. As a result, although $R^{2}$ from two corrected TRMM precipitation datasets has a remarkable increase compared with that from original TRMM precipitation, it is still low in Northwest China. 


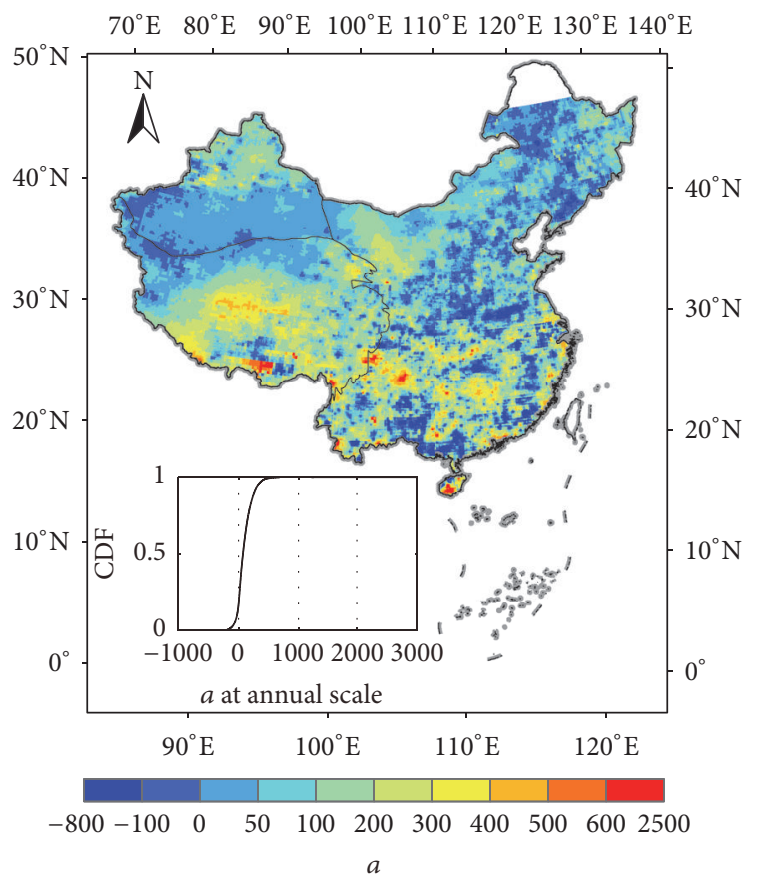

(a)

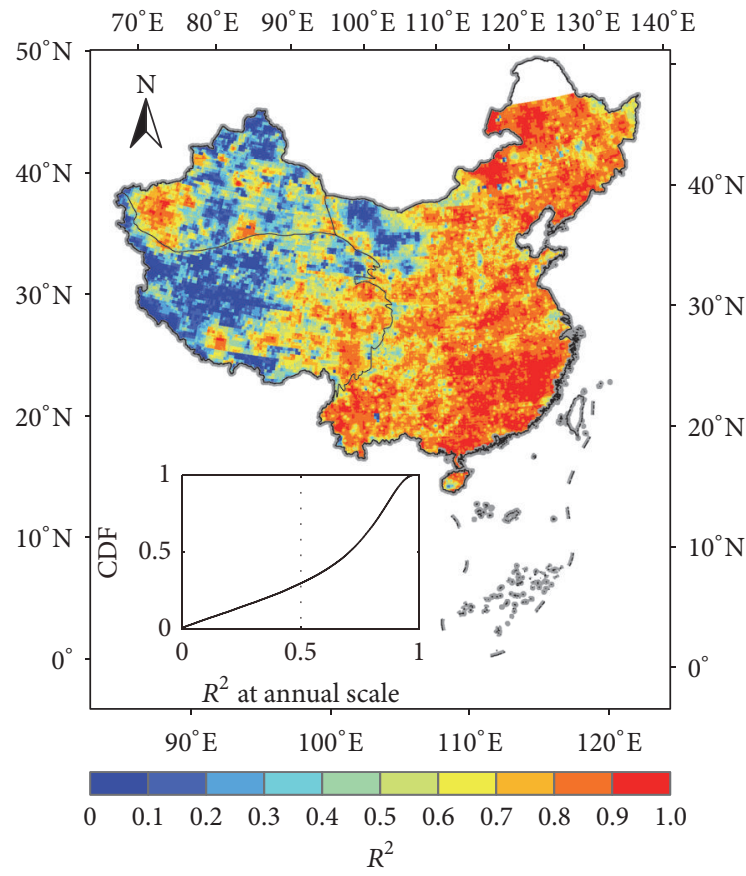

(c)

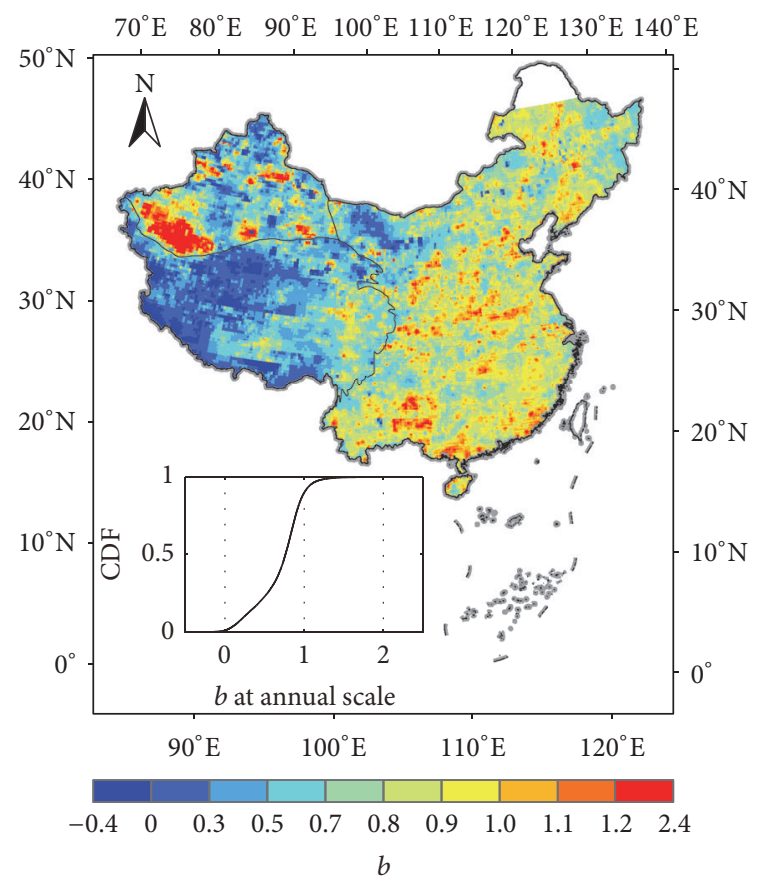

(b)

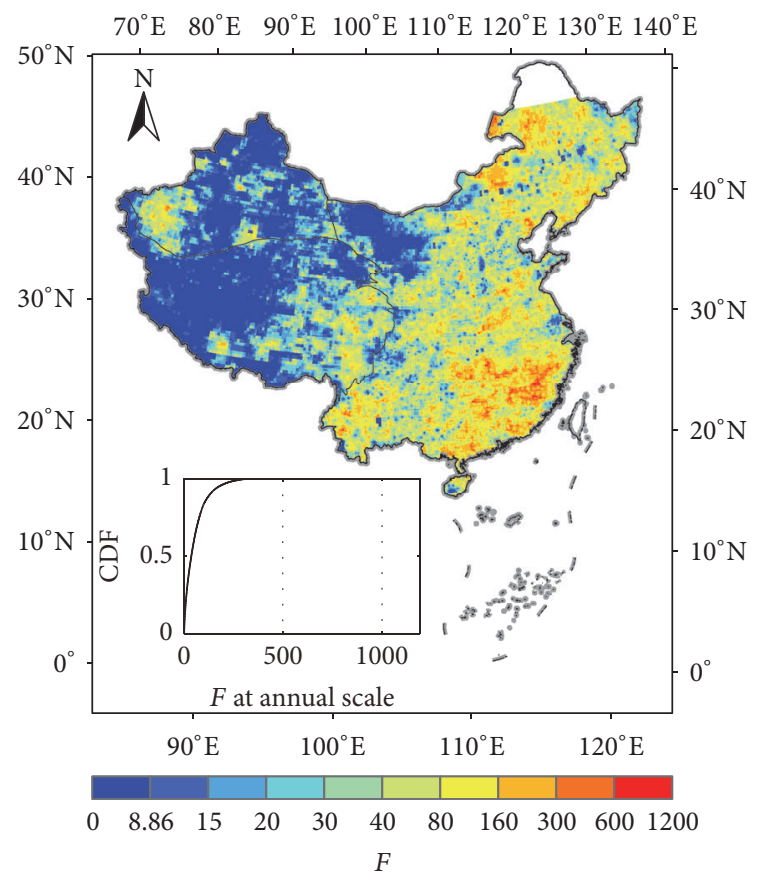

(d)

Figure 5: Annual linear regression model results over China: (a) offset parameter $a$, (b) scale parameter $b$, (c) $R^{2}$, and (d) $F$ statistic.

4.3.2. Validation at Grid Scale. Based on the monthly and annual grid gauge precipitation over China obtained from the spatial interpolation of 839 gauges precipitation in 2014, three TRMM precipitation datasets were validated on the $1 \mathrm{~km}$ resolution grid-by-grid over China. The spatial distributions of annual grid gauge precipitation and original/corrected TRMM precipitation in 2014 are shown in Figure 8. It demonstrates that spatial distribution of grid gauge precipitation and three TRMM precipitation datasets are consistent, and two corrected TRMM precipitation datasets improve the accuracy with statistics more approximated to that of grid gauge precipitation. Besides, the annual precipitation in the three regions was validated by grid-by-grid statistic (Table 1); the results indicate that two corrected TRMM precipitation datasets improve the accuracy of annual precipitation with decreased RMSE, Bias, and increased $R^{2}$, yet there is no 

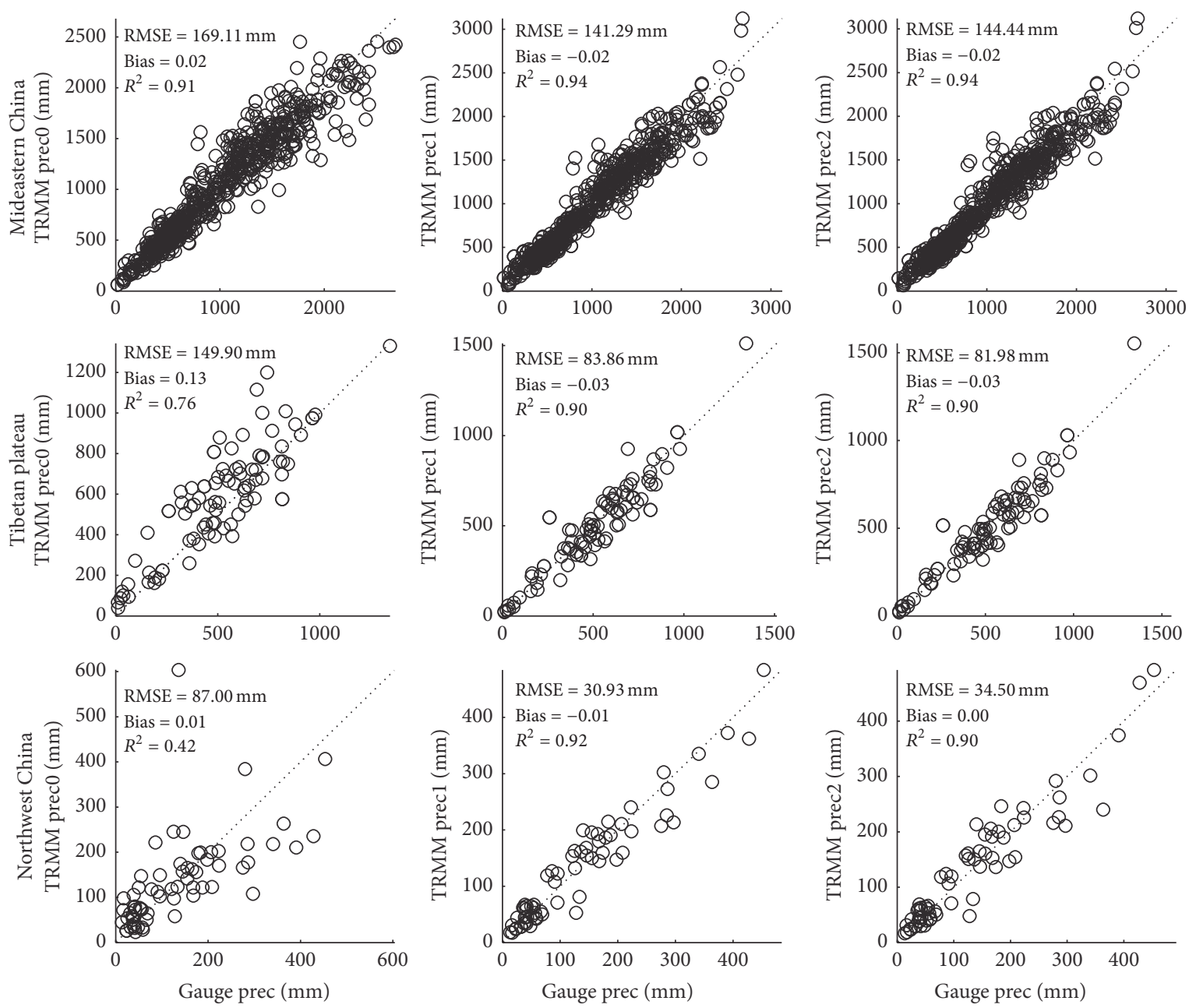

FIGURE 6: Scatterplots of annual gauge precipitation versus original/corrected TRMM precipitation in the three regions at station scale.

TABLE 1: Validation of annual TRMM precipitation in the three regions in 2014 at grid scale.

\begin{tabular}{|c|c|c|c|c|c|}
\hline Regions & Datasets & Mean/mm & $\mathrm{RMSE} / \mathrm{mm}$ & $R^{2}$ & Bias \\
\hline \multirow{4}{*}{ Mideastern China } & Gauge prec & 850.94 & & & \\
\hline & TRMM prec0 & 874.44 & 144.24 & 0.93 & 0.03 \\
\hline & TRMM precl & 838.36 & 130.25 & 0.94 & -0.01 \\
\hline & TRMM prec2 & 837.20 & 129.86 & 0.94 & -0.01 \\
\hline \multirow{4}{*}{ Tibetan plateau } & Gauge prec & 370.88 & & & \\
\hline & TRMM prec0 & 465.51 & 314.98 & 0.37 & 0.36 \\
\hline & TRMM precl & 364.22 & 100.07 & 0.83 & -0.07 \\
\hline & TRMM prec2 & 361.41 & 92.10 & 0.85 & -0.06 \\
\hline \multirow{4}{*}{ Northwest China } & Gauge prec & 129.23 & & & \\
\hline & TRMM prec0 & 106.85 & 88.05 & 0.26 & -0.12 \\
\hline & TRMM precl & 115.78 & 67.03 & 0.45 & -0.05 \\
\hline & TRMM prec2 & 116.81 & 66.93 & 0.45 & -0.05 \\
\hline
\end{tabular}

significant difference between TRMM precl and prec2. It reveals that both LRMs are suitable for the correction of original TRMM precipitation over China at annual scale. However, the validation of annual TRMM precipitation at grid scale is obviously different from that at station scale
(Figure 6). Validation results at grid scale are slightly better than that at station scale with decreased RMSE in Mideastern China. Meanwhile, the validation results at station scale are obviously better than that at grid scale with increased RMSE and decreased $R^{2}$ and Bias in Tibetan plateau and 

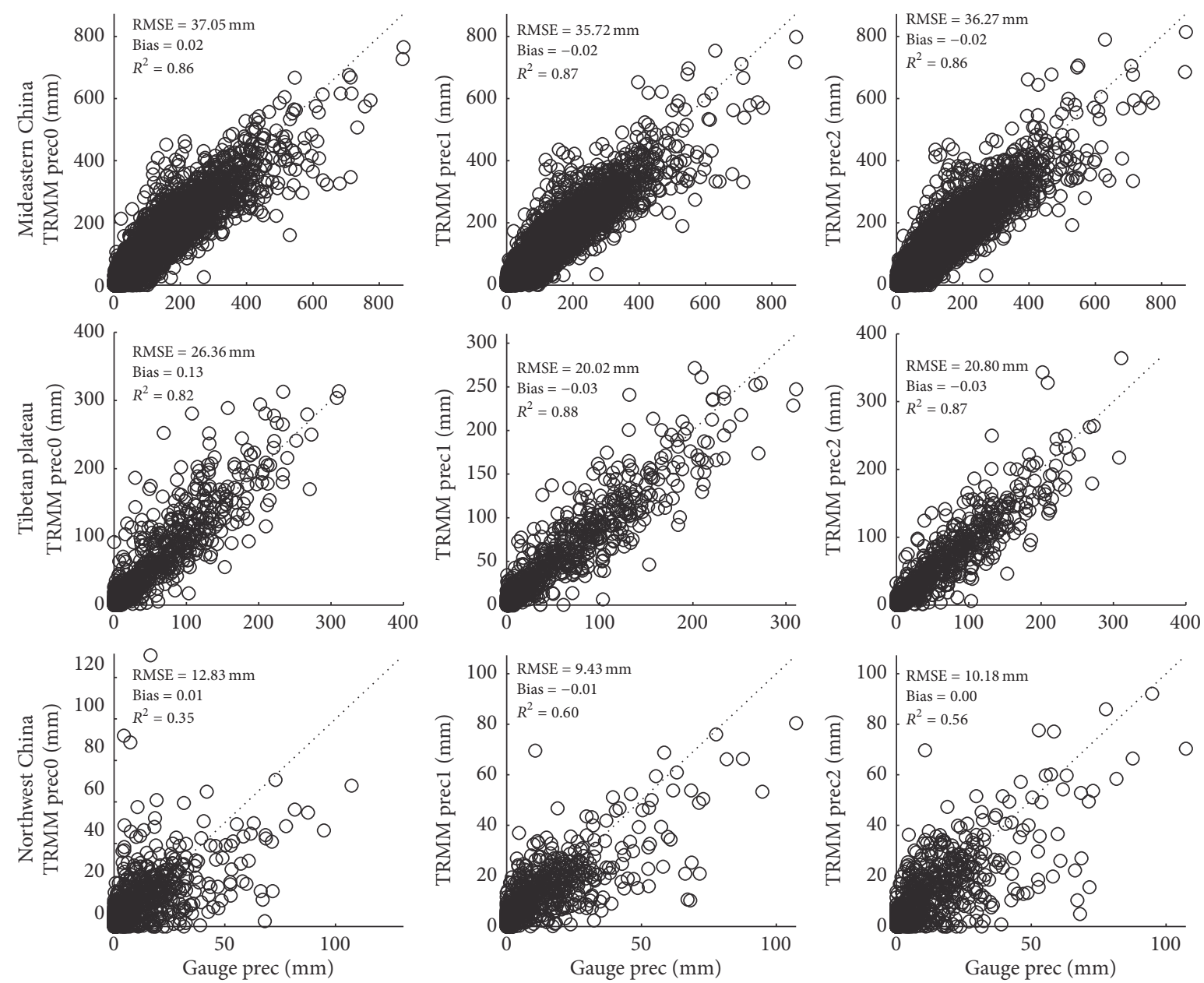

FIGURE 7: Scatterplots of monthly gauge precipitation versus original/corrected TRMM precipitation in the three regions at station scale.

Northwest China. The possible reason is that station gauge precipitation is in good agreement with the corresponding TRMM precipitation in Mideastern China with high PCC, and the grid gauge precipitation obtained from high-density gauge networks is accurate and consistent with TRMM precipitation over Mideastern China. Therefore, the statistics such as RMSE and $R^{2}$ have a slight improvement attributed to the increase of samples from a statistic standpoint (number of grids is dramatically larger than number of stations in Mideastern China). It also indicates that the grid gauge precipitation obtained by IDW interpolation is accurate and reliable in Mideastern China. In contrast, station gauge precipitation does not correlate well with the corresponding TRMM precipitation due to the complicated terrain and climate characteristics in Northwest China and Tibetan plateau. The reason is that the low-density and unevenly distributed gauge networks produce an inaccurate grid gauge precipitation, which contributes to the poor relation between grid gauge precipitation and TRMM precipitation there and result in a larger error of corrected TRMM precipitation. In addition, the interpolated precipitation from 839 gauges precipitation is inevitably different from that from 2257 gauge precipitation and also brings error in the validation of corrected TRMM precipitation. Compared with the validation results at station scale, it can be inferred that there is almost no influence of interpolated precipitation on the corrected TRMM precipitation in Mideastern China, yet the error of interpolated precipitation in Tibetan plateau slightly increases the error of corrected TRMM precipitation. Accordingly, the error of interpolated precipitation obviously reinforces the error of corrected TRMM precipitation in Northwest China due to the apparent deviation between gauge precipitation and original TRMM precipitation at station scale.

Subsequently, the average monthly grid gauge precipitation and original/corrected TRMM precipitation in the three regions in 2014 are shown in Figure 9, and the statistics of monthly areal original/corrected TRMM precipitation versus gauge precipitation in the three regions are listed in Table 2. It should be noted that the statistics in Table 2 were calculated by the monthly areal original/corrected precipitation in the three regions and are different from the aforementioned statistics obtained at station or grid scale in the three regions. Therefore, the RMSE and $R^{2}$ are incomparable to those in Figure 7. The result indicates that original TRMM precipitation is in good agreement with the gauge precipitation in Mideastern China, and it overestimated the precipitation in Tibetan 


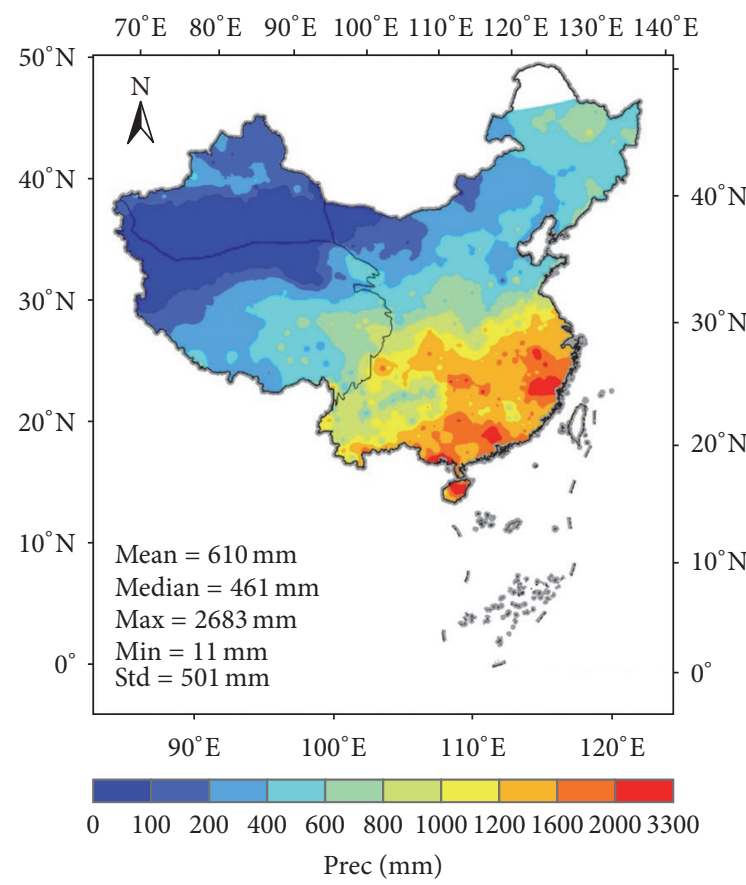

(a)

$70^{\circ} \mathrm{E} \quad 80^{\circ} \mathrm{E} \quad 90^{\circ} \mathrm{E} \quad 100^{\circ} \mathrm{E} 110^{\circ} \mathrm{E} 120^{\circ} \mathrm{E} 130^{\circ} \mathrm{E} 140^{\circ} \mathrm{E}$

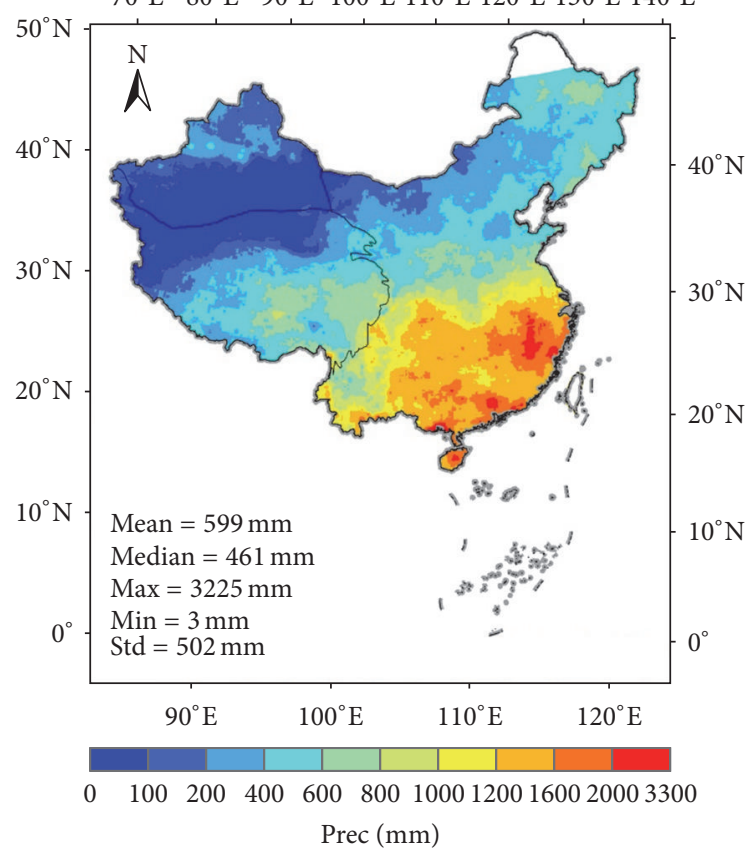

(c)

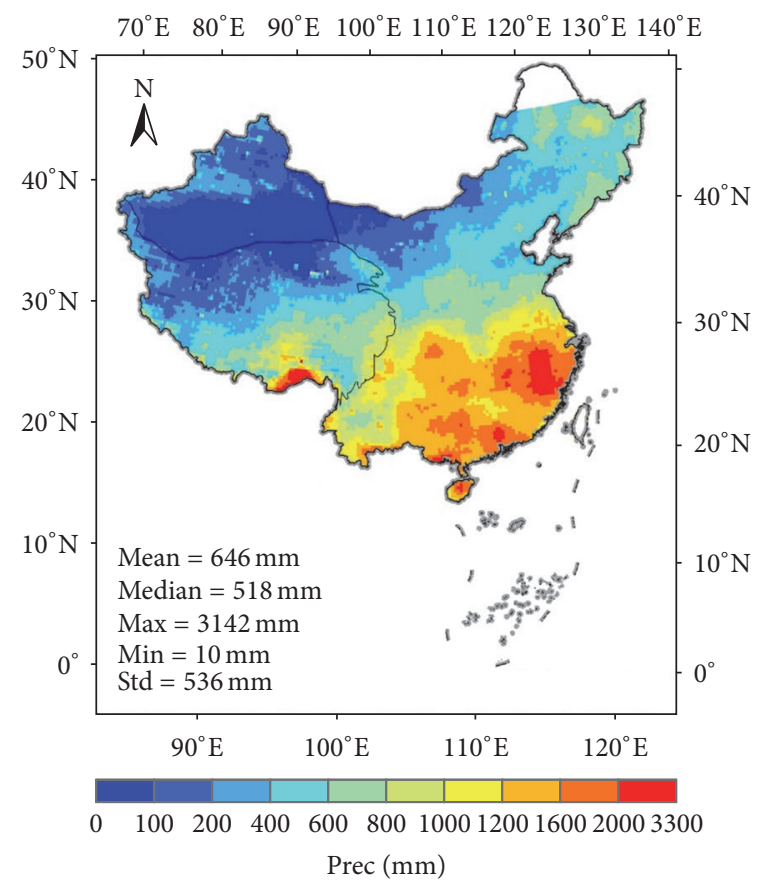

(b)

$50^{\circ} \mathrm{N} 70^{\circ} \mathrm{E} 80^{\circ} \mathrm{E} 90^{\circ} \mathrm{E} 100^{\circ} \mathrm{E} 110^{\circ} \mathrm{E} 120^{\circ} \mathrm{E} 130^{\circ} \mathrm{E} 140^{\circ} \mathrm{E}$

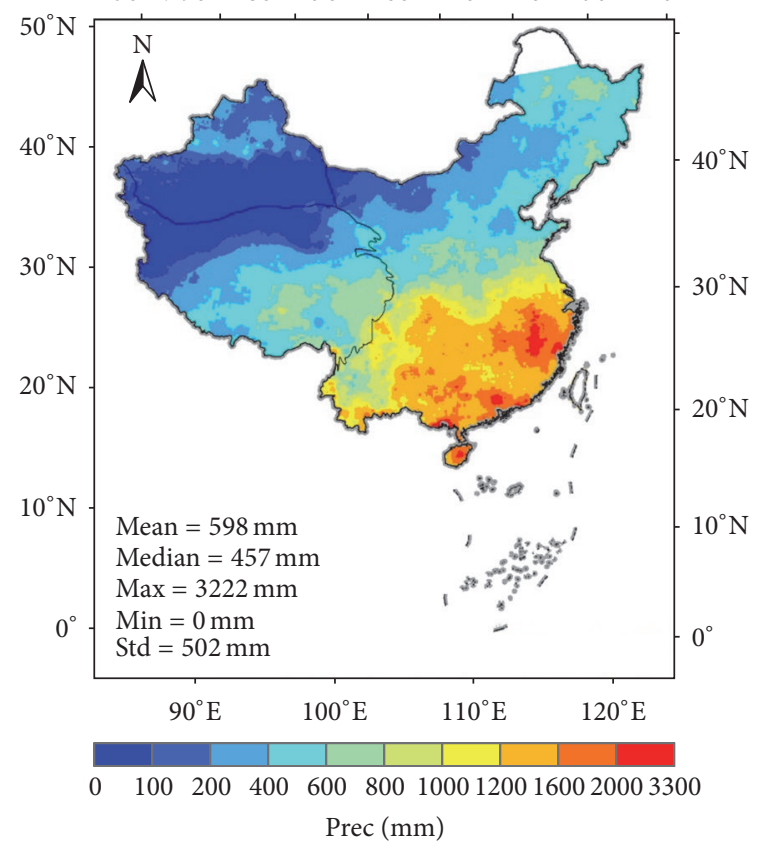

(d)

FIGURE 8: Comparison of spatial distribution of annual gauge precipitation (a), original TRMM precipitation (b), and corrected TRMM precipitation obtained from monthly (c) and annual (d) LRMs in 2014 over China mainland.

Plateau and Northwest China during flooding season (JulSep) and dry month (Jan-Mar), separately. Moreover, two corrected TRMM precipitation datasets have improved the accuracy of TRMM precipitation significantly with approximated mean areal precipitation in the three regions, yet the improvement in Northwest China is insignificant. The reason is that the relation between gauge precipitation and TRMM precipitation is uncertain attributed to the low-density gauge networks and scarce precipitation there, which results in uncertainty in two LRMs.

\section{Conclusions and Remarks}

TRMM $3 \mathrm{~B} 42 \mathrm{~V} 7$ is an important remotely sensed precipitation products for precipitation estimation with high temporal-spatial resolution. In this study, monthly and 
TABLE 2: Validation of monthly original/corrected TRMM precipitation in the three regions in 2014 at regional scale.

\begin{tabular}{|c|c|c|c|c|c|}
\hline Regions & Datasets & Mean/mm & $\mathrm{RMSE} / \mathrm{mm}$ & $R^{2}$ & Bias \\
\hline \multirow{4}{*}{ Mideastern China } & Gauge prec & 70.91 & & & \\
\hline & TRMM prec0 & 72.87 & 4.18 & 1.00 & 0.03 \\
\hline & TRMM precl & 69.86 & 2.71 & 1.00 & -0.01 \\
\hline & TRMM prec2 & 69.77 & 2.85 & 1.00 & -0.01 \\
\hline \multirow{4}{*}{ Tibetan plateau } & Gauge prec & 30.91 & & & \\
\hline & TRMM prec0 & 38.79 & 9.93 & 0.98 & 0.36 \\
\hline & TRMM precl & 30.35 & 5.51 & 0.99 & -0.07 \\
\hline & TRMM prec2 & 30.12 & 4.27 & 0.99 & -0.06 \\
\hline \multirow{4}{*}{ Northwest China } & Gauge prec & 10.77 & & & \\
\hline & TRMM prec0 & 8.90 & 1.79 & 0.90 & -0.12 \\
\hline & TRMM precl & 9.65 & 2.32 & 0.89 & -0.05 \\
\hline & TRMM prec2 & 9.73 & 2.35 & 0.87 & -0.05 \\
\hline
\end{tabular}
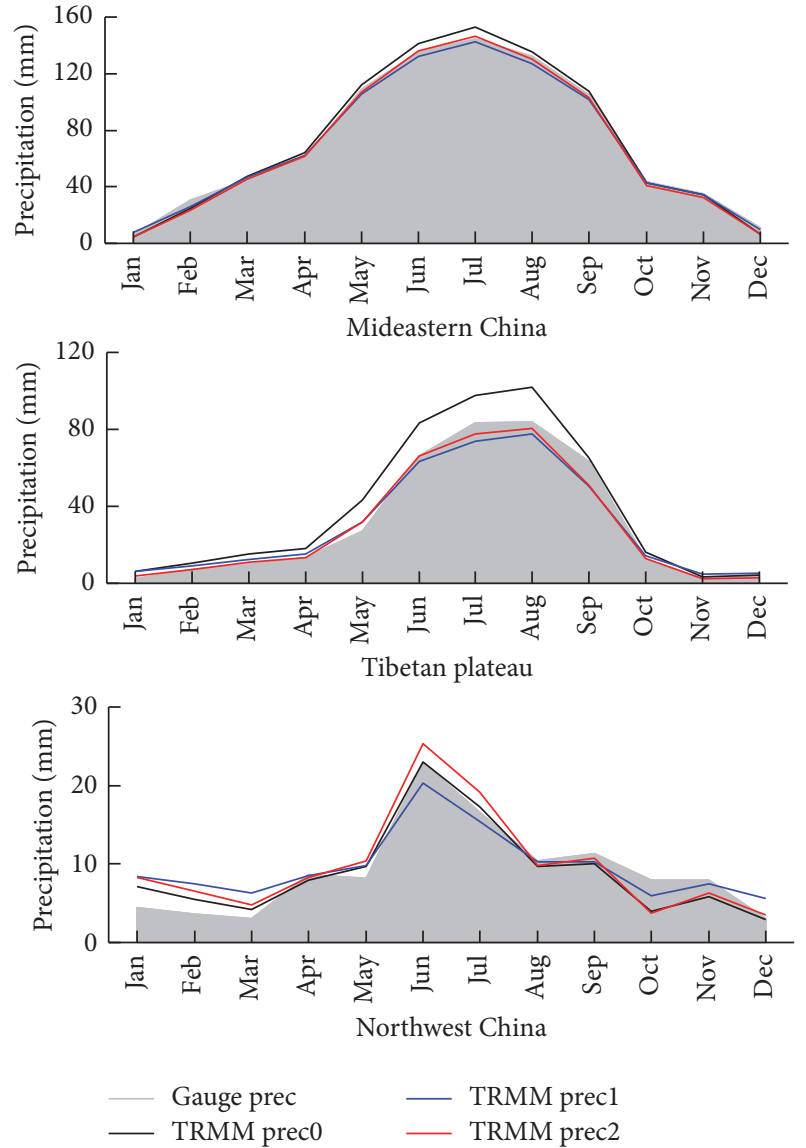

FIGURE 9: Average monthly gauge precipitation and original/corrected TRMM precipitation in the three regions in 2014.

annual LRMs had been constructed to correct and downscale the TRMM precipitation based on the gauge precipitation at 2257 stations over China from 1998 to 2013. Then, the gauge precipitation at 839 out of 2257 station in 2014 was used to validate the corrected TRMM precipitation at station and grid scales.
According to the results of LRMs, monthly LRM is more suitable for the correction of TRMM precipitation over China from a statistical standpoint, since there is less than $0.1 \%$ of China mainland with insignificant $F$ statistic in monthly LRM and about $21 \%$ of China mainland with insignificant $F$ statistic in annual LRM at 0.01 significant level. Most of grids with insignificant $F$ statistic concentrate in Northwest China and Tibetan plateau. Additionally, the offset parameter $a$ and scale parameter $b$ are more random and uncertain attributed to the shorter length of input series in annual LRM $(n=16)$ than that in monthly LRM $(n=192)$, especially in Northwest China and Tibetan plateau.

Validations of original/corrected TRMM precipitation indicate that two LRMs have obviously improved the accuracy of TRMM precipitation with acceptable error, and monthly LRM performs slightly better than annual LRM in Mideastern China. Although the performance of corrected TRMM precipitation from LRMs has been increased in Northwest China and Tibetan plateau, the error of corrected TRMM precipitation is still significant due to the larger deviation between gauge precipitation and TRMM precipitation, which reinforces the error of interpolated precipitation, especially in Northwest China.

Consequently, it can be concluded that LRMs are essential accesses to obtain real-time and high spatial-temporal precipitation from open access TRMM precipitation in Mideastern China, which will be meaningful for the hydrological modelling and water resource management in the regions without (open access) gauge stations. Furthermore, it reveals that the performance of corrected TRMM precipitation significantly depended on the relation between original TRMM precipitation and gauge precipitation. The reasons are that (1) the potential hypothesis in LRM is that there is good linear relation between dependent variable and independent variable. Thus the poor relation between gauge precipitation and TRMM precipitation will lead to significant error of corrected TRMM precipitation. (2) The poor relation between gauge precipitation and TRMM precipitation at station scale will be amplified by the spatial interpolation and has a profound influence on the accuracy of corrected TRMM precipitation, especially in the regions with sparse gauge networks. 


\section{Competing Interests}

The authors declare that there is no conflict of interests regarding the publication of this paper.

\section{Acknowledgments}

This work was supported by the Major Research Plan of the National Natural Science Foundation of China (no. 91547209), General Program of the National Natural Science Foundation of China (no. 41571037), and Open Research Foundation from State Key Laboratory of Simulation and Regulation of Water Cycle in River Basin (no. 2015ZY02).

\section{References}

[1] J. R. Gat and P. L. Airey, "Stable water isotopes in the atmosphere/biosphere/lithosphere interface: scaling-up from the local to continental scale, under humid and dry conditions," Global and Planetary Change, vol. 51, no. 1-2, pp. 25-33, 2006.

[2] S. Chen, Y. Hong, Q. Cao et al., "Similarity and difference of the two successive V6 and V7 TRMM multisatellite precipitation analysis performance over China," Journal of Geophysical Research Atmospheres, vol. 118, no. 23, pp. 13060-13074, 2013.

[3] P. Salio, M. P. Hobouchian, Y. García Skabar, and D. Vila, "Evaluation of high-resolution satellite precipitation estimates over southern South America using a dense rain gauge network," Atmospheric Research, vol. 163, pp. 146-161, 2015.

[4] P. T. Nastos, J. Kapsomenakis, and K. M. Philandras, "Evaluation of the TRMM 3B43 gridded precipitation estimates over Greece," Atmospheric Research, vol. 169, pp. 497-514, 2016.

[5] G. J. Huffman, R. F. Adler, P. Arkin et al., "The Global Precipitation Climatology Project (GPCP) combined precipitation dataset," Bulletin of the American Meteorological Society, vol. 78, no. 1, pp. 5-20, 1997.

[6] M. Chen, W. Shi, P. Xie et al., "Assessing objective techniques for gauge-based analyses of global daily precipitation," Journal of Geophysical Research Atmospheres, vol. 113, no. 4, Article ID D04110, 2008.

[7] N. Ghajarnia, A. Liaghat, and P. Daneshkar Arasteh, "Comparison and evaluation of high resolution precipitation estimation products in Urmia Basin-Iran," Atmospheric Research, vol. 158159, pp. 50-65, 2015.

[8] T. D. Mitchell and P. D. Jones, "An improved method of constructing a database of monthly climate observations and associated high-resolution grids," International Journal of Climatology, vol. 25, no. 6, pp. 693-712, 2005.

[9] U. Schneider, T. Fuchs, A. Meyer-Christoffer, B. Rudolf, and Global Precipitation Analysis Products of the GPCC, Global Precipitation Climatology Centre (GPCC), DWD, Internet Publication, 2008.

[10] A. Dai, I. Y. Fung, and A. D. Del Genio, "Surface observed global land precipitation variations during 1900-88," Journal of Climate, vol. 10, no. 11, pp. 2943-2962, 1997.

[11] M. New, M. Hulme, and P. Jones, "Representing twentiethcentury space-time climate variability-part I: development of a 1961-1990 mean monthly terrestrial climatology," Journal of Climate, vol. 12, no. 2-3, pp. 829-856, 1999.

[12] M. Chen, P. Xie, J. E. Janowiak, and P. A. Arkin, "Global land precipitation: a 50-yr monthly analysis based on gauge observations," Journal of Hydrometeorology, vol. 3, no. 3, pp. 249-266, 2002.
[13] P. Xie, M. Chen, S. Yang et al., "A gauge-based analysis of daily precipitation over East Asia," Journal of Hydrometeorology, vol. 8, no. 3, pp. 607-626, 2007.

[14] A. Dai and T. M. L. Wigley, "Global patterns of ENSO-induced precipitation," Geophysical Research Letters, vol. 27, no. 9, pp. 1283-1286, 2000.

[15] J. O. Roads, S.-C. Chen, and F. Fujioka, "ECPC's weekly to seasonal global forecasts," Bulletin of the American Meteorological Society, vol. 82, no. 4, pp. 639-658, 2001.

[16] A. Yatagai, P. Xie, and A. Kitoh, "Utilization of a new gaugebased daily precipitation dataset over monsoon Asia for validation of the daily precipitation climatology simulated by the MRI/JMA 20-km-mesh AGCM," SOLA, vol. 1, pp. 193-196, 2005.

[17] E. E. Ebert, J. E. Janowiak, and C. Kidd, "Comparison of nearreal-time precipitation estimates from satellite observations and numerical models," Bulletin of the American Meteorological Society, vol. 88, no. 1, pp. 47-64, 2007.

[18] P. A. Arkin and Pingping Xie, "The Global Precipitation Climatology Project: first algorithm intercomparison project," Bulletin of the American Meteorological Society, vol. 75, no. 3, pp. 401419, 1994.

[19] G. J. Huffman, R. F. Adler, M. M. Morrissey et al., "Global precipitation at one-degree daily resolution from multisatellite observations," Journal of Hydrometeorology, vol. 2, no. 1, pp. 36$50,2001$.

[20] K.-L. Hsu, X. Gao, S. Sorooshian, and H. V. Gupta, "Precipitation estimation from remotely sensed information using artificial neural networks," Journal of Applied Meteorology, vol. 36, no. 9, pp. 1176-1190, 1997.

[21] S. Sorooshian, K.-L. Hsu, X. Gao, H. V. Gupta, B. Imam, and D. Braithwaite, "Evaluation of PERSIANN system satellitebased estimates of tropical rainfall," Bulletin of the American Meteorological Society, vol. 81, no. 9, pp. 2035-2046, 2000.

[22] G. J. Huffman, R. F. Adler, D. T. Bolvin et al., "The TRMM Multisatellite Precipitation Analysis (TMPA): quasi-global, multiyear, combined-sensor precipitation estimates at fine scales," Journal of Hydrometeorology, vol. 8, no. 1, pp. 38-55, 2007.

[23] G. J. Huffman, R. F. Adler, D. T. Bolvin, and E. J. Nelkin, "TRMM Multi-satellite Precipitation Analysis (TMPA)," in Satellite Rainfall Applications for Surface Hydrology, pp. 3-22, Springer, Amsterdam, The Netherlands, 2010.

[24] M. Pan, H. Li, and E. Wood, "Assessing the skill of satellitebased precipitation estimates in hydrologic applications," Water Resources Research, vol. 46, no. 9, Article ID W09535, 2010.

[25] X.-H. Li, Q. Zhang, and C.-Y. Xu, "Suitability of the TRMM satellite rainfalls in driving a distributed hydrological model for water balance computations in Xinjiang catchment, Poyang lake basin," Journal of Hydrology, vol. 426-427, pp. 28-38, 2012.

[26] L. Li, Y. Hong, J. Wang et al., "Evaluation of the real-time TRMM-based multi-satellite precipitation analysis for an operational flood prediction system in Nzoia Basin, Lake Victoria, Africa," Natural Hazards, vol. 50, no. 1, pp. 109-123, 2009.

[27] A. K. Sahoo, J. Sheffield, M. Pan, and E. F. Wood, "Evaluation of the Tropical Rainfall Measuring Mission Multi-Satellite Precipitation Analysis (TMPA) for assessment of large-scale meteorological drought," Remote Sensing of Environment, vol. 159, pp. 181-193, 2015.

[28] Y. Malhi, L. E. O. C. Aragão, D. Galbraith et al., "Exploring the likelihood and mechanism of a climate-change-induced dieback of the Amazon rainforest," Proceedings of the National 
Academy of Sciences of the United States of America, vol. 106, no. 49, pp. 20610-20615, 2009.

[29] S. W. Nesbitt, E. J. Zipser, and C. D. Kummerow, "An examination of version- 5 rainfall estimates from the TRMM Microwave Imager, precipitation radar, and rain gauges on global, regional, and storm scales," Journal of Applied Meteorology, vol. 43, no. 7, pp. 1016-1036, 2004.

[30] Y. Tian and C. D. Peters-Lidard, "A global map of uncertainties in satellite-based precipitation measurements," Geophysical Research Letters, vol. 37, no. 24, Article ID L24407, 2010.

[31] E. Habib, A. Henschke, and R. F. Adler, "Evaluation of TMPA satellite-based research and real-time rainfall estimates during six tropical-related heavy rainfall events over Louisiana, USA," Atmospheric Research, vol. 94, no. 3, pp. 373-388, 2009.

[32] S. Chen, Y. Hong, J. J. Gourley et al., "Evaluation of the successive V6 and V7 TRMM multisatellite precipitation analysis over the Continental United States," Water Resources Research, vol. 49, no. 12, pp. 8174-8186, 2013.

[33] Z. Yu, H. Yu, P. Chen, C. Qian, and C. Yue, "Verification of tropical cyclone-related satellite precipitation estimates in mainland China," Journal of Applied Meteorology and Climatology, vol. 48, no. 11, pp. 2227-2241, 2009.

[34] F. Lo Conti, K.-L. Hsu, L. V. Noto, and S. Sorooshian, "Evaluation and comparison of satellite precipitation estimates with reference to a local area in the Mediterranean Sea," Atmospheric Research, vol. 138, pp. 189-204, 2014.

[35] S. Javanmard, A. Yatagai, M. I. Nodzu, J. Bodaghjamali, and H. Kawamoto, "Comparing high-resolution gridded precipitation data with satellite rainfall estimates of TRMM-3B42 over Iran," Advances in Geosciences, vol. 25, pp. 119-125, 2010.

[36] P.-S. Katiraie-Boroujerdy, N. Nasrollahi, K.-L. Hsu, and S. Sorooshian, "Evaluation of satellite-based precipitation estimation over Iran," Journal of Arid Environments, vol. 97, pp. 205219, 2013.

[37] S. Moazami, S. Golian, M. R. Kavianpour, and Y. Hong, "Comparison of PERSIANN and V7 TRMM multi-satellite precipitation analysis (TMPA) products with rain gauge data over Iran," International Journal of Remote Sensing, vol. 34, no. 22, pp. 8156-8171, 2013.

[38] V. M. Mantas, Z. Liu, C. Caro, and A. J. S. C. Pereira, "Validation of TRMM multi-satellite precipitation analysis (TMPA) products in the Peruvian Andes," Atmospheric Research, vol. 163, pp. 132-145, 2015.

[39] H. Feidas, "Validation of satellite rainfall products over Greece," Theoretical and Applied Climatology, vol. 99, no. 1-2, pp. 193-216, 2010.

[40] M. Almazroui, "Calibration of TRMM rainfall climatology over Saudi Arabia during 1998-2009," Atmospheric Research, vol. 99, no. 3-4, pp. 400-414, 2011.

[41] Y. Shen, A. Xiong, Y. Wang, and P. Xie, "Performance of highresolution satellite precipitation products over China," Journal of Geophysical Research Atmospheres, vol. 115, no. 2, Article ID D02114, 2010.

[42] W. Yuan, B. Xu, Z. Chen et al., "Validation of China-wide interpolated daily climate variables from 1960 to 2011," Theoretical and Applied Climatology, vol. 119, no. 3, pp. 689-700, 2015.

[43] T. Zhou, R. Yu, H. Chen, A. Dai, and Y. Pan, "Summer precipitation frequency, intensity, and diurnal cycle over China: a comparison of satellite data with rain gauge observations," Journal of Climate, vol. 21, no. 16, pp. 3997-4010, 2008.
[44] W. W. Immerzeel, M. M. Rutten, and P. Droogers, "Spatial downscaling of TRMM precipitation using vegetative response on the Iberian Peninsula," Remote Sensing of Environment, vol. 113, no. 2, pp. 362-370, 2009.

[45] S. Jia, W. Zhu, A. Lu, and T. Yan, "A statistical spatial downscaling algorithm of TRMM precipitation based on NDVI and DEM in the Qaidam Basin of China," Remote Sensing of Environment, vol. 115, no. 12, pp. 3069-3079, 2011.

[46] Z. Duan and W. G. M. Bastiaanssen, "First results from Version 7 TRMM 3B43 precipitation product in combination with a new downscaling-calibration procedure," Remote Sensing of Environment, vol. 131, pp. 1-13, 2013.

[47] D. Chen, T. Ou, L. Gong et al., "Spatial interpolation of daily precipitation in China: 1951-2005," Advances in Atmospheric Sciences, vol. 27, no. 6, pp. 1221-1232, 2010.

[48] O. Babak and C. V. Deutsch, "Statistical approach to inverse distance interpolation," Stochastic Environmental Research and Risk Assessment, vol. 23, no. 5, pp. 543-553, 2009.

[49] J. Meng, L. Li, Z. Hao, J. Wang, and Q. Shao, "Suitability of TRMM satellite rainfall in driving a distributed hydrological model in the source region of Yellow River," Journal of Hydrology, vol. 509, pp. 320-332, 2014. 

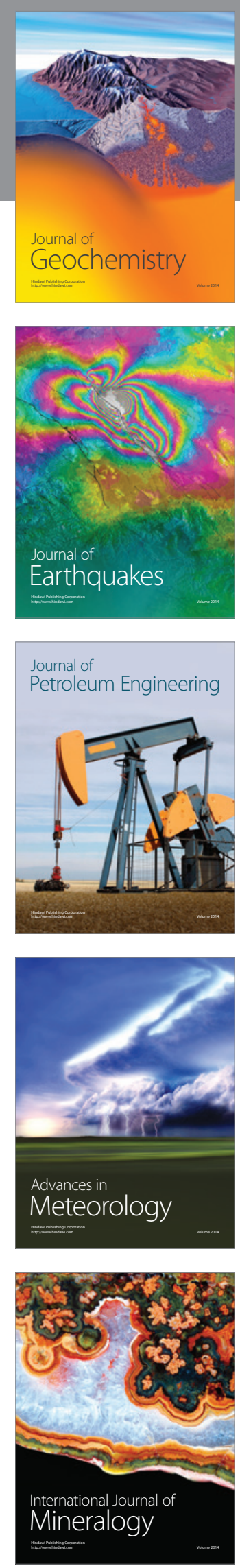
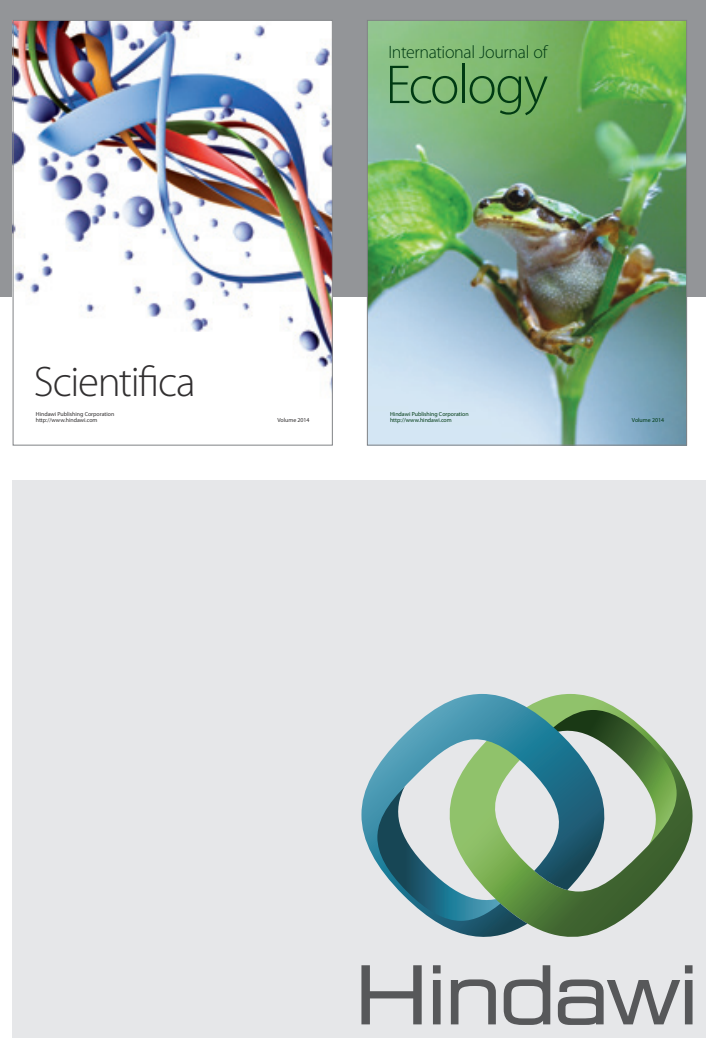

Submit your manuscripts at

http://www.hindawi.com
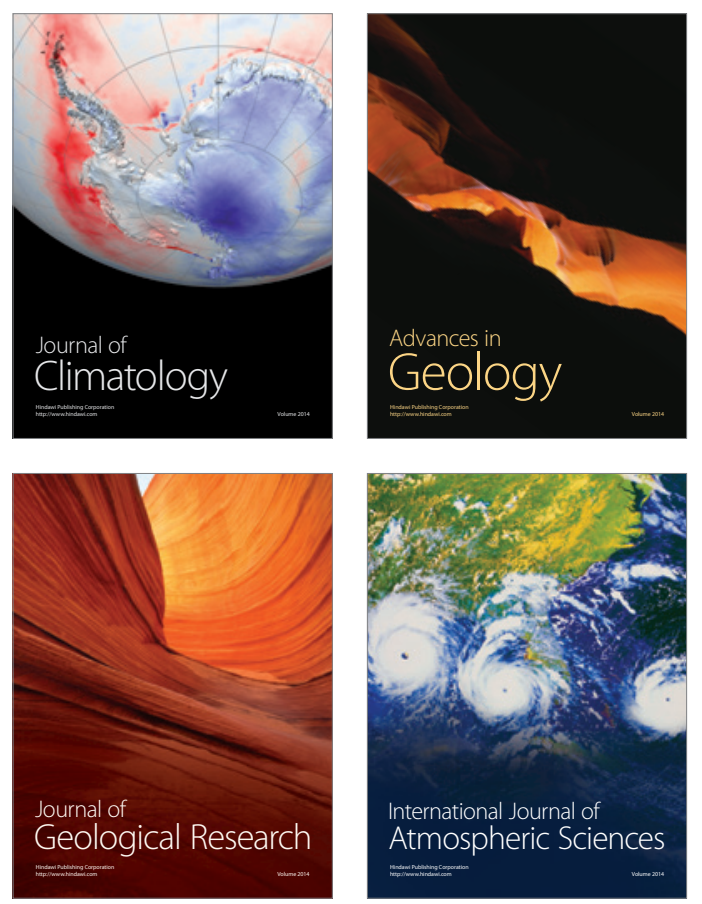

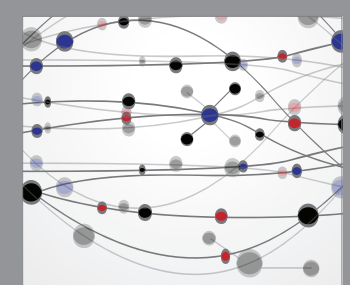

The Scientific

\section{World Journal}
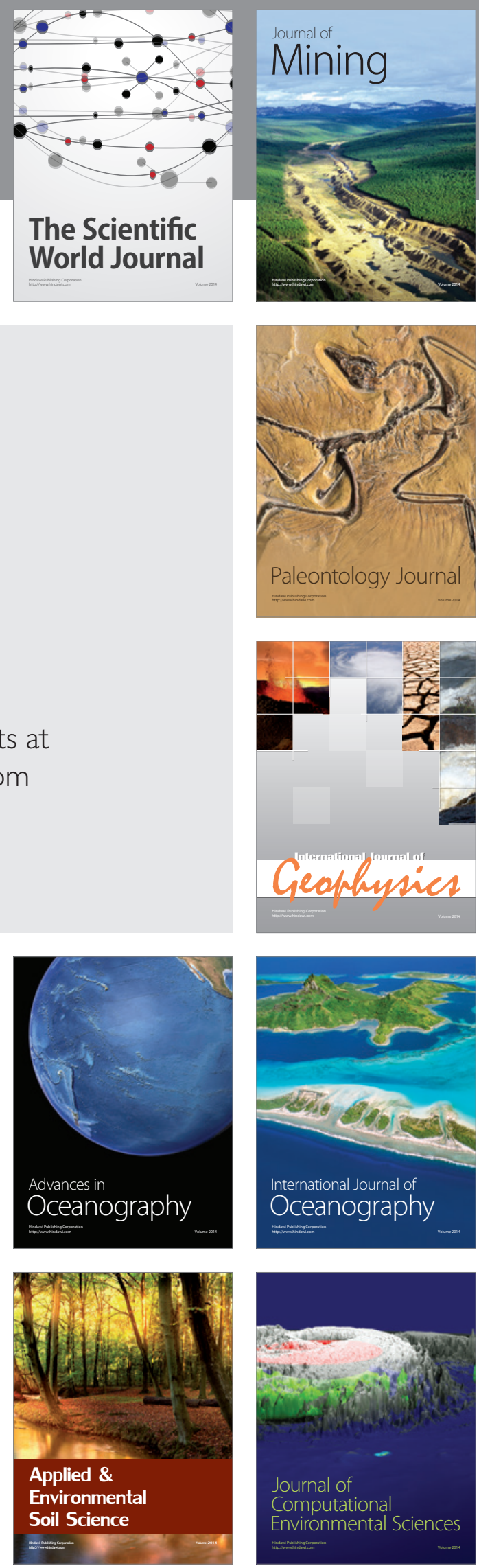